\title{
USING ETHNOGRAPHY IN STRATEGIC CONSUMER RESEARCH
}

Paper number 02/02

\author{
Richard Elliott ${ }^{1}$ \\ Centre for Consumer Research, University of Exeter \\ $\&$ \\ Nick Jankel-Elliott \\ Happy Dog Group, London
}

\begin{abstract}
This paper describes how ethnographic and quasi-ethnographic research methods can be used in order to understand in depth the lived experience of consumers. A range of approaches are discussed and examples of their use in consumer research are given. Two case studies of ethnographic methods being used in strategic commercial research projects are described in detail. The implications for utilising ethnography in order to obtain managerially actionable insights are discussed.
\end{abstract}

${ }^{1}$ School of Business and Economics, Streatham Court, Rennes Drive

Exeter, EX4 4PU, UK Phone: +44 1392264522 Fax: +44 1392264425

E-mail: Richard.Elliott@exeter.ac.uk

ISSN 1473 - 2939 


\section{USING ETHNOGRAPHY IN STRATEGIC CONSUMER RESEARCH}

\section{Introduction}

The 'interpretive turn' in marketing has led to renewed interest in research methods which are based on developments in the wider social sciences. This paper looks at the resurgence in the use of arguably the oldest methodology of social investigation, ethnography. Fundamental to using these methods in marketing is a concern for studying the lived experience of the consumer as a social being, this 'Brand Ecology' (Percy et al., 2001) considers not just the attitudinal, emotional and behavioural aspects of brand consumption, but explores how this brand-related behaviour integrates with wider social and cultural experience in the life-world of the active consumer. We then go on to describe two case examples of these methods being used in strategic consumer research.

\section{The Origins of Ethnography}

In a striking echo of the usual practices of managers commissioning market research, the first approach to the gathering of data from the field was the 'armchair method' (Van Maanen, 1988) used by scholars in Britain and France to understand the 'alien worlds' of their empires. This involved District Commissioners, the local representatives of the colonial power, being used as fieldworkers to gather data and send it home for analysis. This evolved into the 'Notes and Queries' approach which standardised the questions to be asked of local informants into a guidebook published in 1874 (Van Maanen, 1988). Attempts to gain first hand information started with 
short trips to the field to interview paid informants (usually through interpreters) on a limited range of issues. These 'veranda anthropologists' were followed by the development of the ethnographic methods used today when Malinowski was forced by the outbreak of the first world war to remain in close living proximity with the natives of the Trobriand Islands in the South Pacific. This enforced immersion for several years in the daily lives of the islanders led to the seminal text 'Argonauts of the Western Pacific' (Malinowski, 1922) and to his famous advice on ethnographic method: the fieldworker must spend at least a year in the field, use the local vernacular, live apart from his own kind, and above all, make the psychological transference whereby "they" becomes "we" (Stocking, 1983). A significant development occurred in the 1930's when the critical sociologists of the Chicago School began exploring the culture of the cities as if it were an exotic far-away land. This 'streetcorner' sociology studied the 'deviant subcultures' of American in the great depression, focusing on direct participation and discovery of the particular (Downes and Rock, 1982).

\section{Some Basic Assumptions of Ethnography}

We can now derive some principles of what is involved in doing ethnography, the first of which is that it entails the study of behaviour in natural settings, "getting the seat of your pants dirty...in the real world, not the library" (Fielding, 1993 p157). The second is that no adequate knowledge of social behaviour can be developed without an understanding of the symbolic world of the subjects of study, seeing the world through their eyes and using their shared meanings, the empathetic process of 
verstehen. This involves learning the language in use: dialect, jargon, special uses of words, neologisms. The second principle is that it requires extended presence in the field, "long-term immersion in context increases the likelihood of spontaneously encountering important moments in the ordinary events of consumers' daily lives and of experiencing revelatory incidents" (Arnould and Wallendorf, 1994). A third principle is that of participation in cultural life in order to 'walk a mile in their shoes' and develop an understanding of cultural/symbolic meanings and "local rules" (Hochschild, 1979).

Ethnography makes use of small samples of informants: opportunistic samples whoever seems likely to give 'rich' data, judgmental samples - seeking out people who may have specialist knowledge in an area. It is probably impossible for an ethnographer to obtain a random sample as he/she will be unable to build a rapport with all informants and without rapport the information is likely to be of poor quality (Agar, 1996). Most importantly, ethnographers are seeking to develop a "thick description" of social behaviour, where he/she is faced with " a multiplicity of complex conceptual structures, many of them superimposed upon or knotted into one another, which are at once strange, irregular, and inexplicit and which he must contrive somehow first to grasp and then to render" (Geertz 1973, p10). When tackling this complexity we must go for depth not breadth, understanding not prediction. Alvesson and Skoldberg (2000) distinguish between 'inductive ‘ ethnography which emphasises data and strongly focuses on method as the key to good research, and 'interpretive' ethnography which puts the emphasis on bold interpretation. Here we are concentrating on interpretive ethnography. 


\section{Ethnographic Methods}

\section{Participant observation}

The essence of ethnographic methods consists primarily in participant observation, a approach in which "you are directly involved in community life, observing and talking with people as you learn from them their view of reality" (Agar, 1996, p. 163). A typology of levels of involvement in observation identifies four modes: the complete participant, the participant-as-observer, the observer-as-participant, and the complete observer (Gold, 1958). However, as Hammersly and Atkinson (1983) point out, the two end-points can be severely limited in the quality of information that can be gathered, and the difference between the two middle modes is highly questionable. What we can say is that the ideal approach attempts to minimise the effect of the researcher on the researched and maximises the depth of information that is obtained. This can vary from a hidden or disguised voyeur (as described below in relation to video-taping) to the active participant who acts as a member not as a researcher "so as not to alter the flow of the interaction unnaturally" (Adler and Adler, 1994, p. 380).

In commercial ethnography, or quasi-ethnography (see below), we are often unable to truly participate with consumers, e.g. actually live with them as a member of the family, so we are forced to develop a whole host of approaches that allow us some access to their lived experience. 


\section{Non-participant Observation}

In some instances, it may be undesirable to attempt to achieve participant observer status, where the introduction of an outsider may disturb or destroy the essence of the behaviour that is being studied, e.g. small-group behaviour, person-object interactions which are habitual and pre-scripted (Arnould and Wallendorf, 1994). Observation of parents changing the nappies of their babies was able to yield actionable information on nappy-design (Alsop, 1986) and observation of shopping behaviour by videotape has been used to drive shop-layout decisions by Asda supermarkets in the UK.

A novel approach to non-intrusive data collection is described by Rust (1993) where in order to gather data on parents and children shopping together, researchers posed as shoppers in supermarkets and toy shops, wait in aisle for a parent-child group. "On seeing a shopping party enter the aisle, they would estimate the child's age, record some basic information about the shoppers, and then take notes on what they said and did. As soon as the party left the aisle, the observers would finish up the notes and wait until the next party appeared" (Rust, 1993, p.66). Two hundred records were gathered and then used to develop a number of marketing management implications.

\section{Interviews}

Participant observation is rarely used without a number of other data-gathering methods, most notably interviews, both formal and informal. Asking people why they are doing what they are doing is a necessary component in developing an 
understanding of their situated behaviour and although such data should not necessarily be privileged over other inputs. A key aspect of ethnographic interviews is the focus on the use of non-directive questions, "designed as triggers that stimulate the interviewee into talking about a particular broad area" (Hammersley and Atkinson, 1983 p.113). Typical interview approaches are the 'daily routine' and the 'life history' interviews, which have been used in consumer research to explore such issues as the consumption routines of members of an extreme Buddhist sect (Wattanasuwan and Elliott, 1999) and role of consumption in acculturation (Lui and Elliott, 2002). Questioning need not be restricted to non-directive forms, as often one will want to test out hypotheses arising from on-going interpretations, as well as to fill-in specific information gaps.

\section{Informal Interviews and Casual Conversations}

Much of the richest data which ethnography can capture comes from the whole realm of informal talk between researcher and informants, what Agar (1996, p.158) calls "hanging out" and places at the centre of ethnographic fieldwork. The essence of the informal interview is that the researcher does not have a written list of questions but rather a repertoire of question-asking strategies to select from when the moment seems appropriate. Also it is informal because the questioning may take place in a wide variety of contexts, e.g. while working with informants on a shared task, while drinking coffee in a social situation, while watching television. The objective is to get as "experience-near" as possible (Geertz, 1973), allowing the informant to control the discussion: "everything is negotiable. The informant can criticize a question, correct 
it, point out that it is sensitive, or answer in any way they want to." (Agar, $1996 \mathrm{p}$. 140).

A supplementary method is to use "Bait", that is to ask questions that strongly suggest an answer and are used to check emergent interpretations by leading the respondent towards modifying or contradicting a statement (Agar, 1996)

\section{Informant Dairies}

As a way into informal interviews, informants can be asked to keep diaries relevant to the research area, which can then be used to talk-through the experiences recorded. This has been done to explore the specific behaviour and the associated emotions experienced when gender-switching in an on-line dating game (Chen, Davies and Elliott, 2002): and together with a photo-collage constructed by informants, used to explore the use of goods and advertisements as symbolic resources for the construction of gender identity (Wattansuwan and Elliott, 1997).

When used in combination with other data-collection methods diaries can expose important differences. For example, Lever (1981) studied children's play and used both diaries and questionnaires, which showed different levels of gender stereotyping. She concluded that asking what they 'usually do' in the questionnaires led to greater gender differences than asking what they 'actually did' in the diaries due to the different levels of abstraction inherent in the data collection method. 


\section{Quasi-ethnography and Audience Ethnography}

In consumer research it is often prohibitively expensive to carry out true participant observation over extended periods of time, particularly in relation to children and teenagers and to media consumption. Consequently a whole range of techniques have been developed to approximate to ethnography. Some of these are described in the case studies below, but some examples of creative approaches to consumer and audience research are described here.

In order to explore the symbolic meaning of the British pub, Clarke et al., (1998) used a combination of questionnaires and loosely-structured in-depth discussions in the pub itself. Informant responses where audio-taped and subsequently content-analysed using the semiotic cube.

The challenging topic of the service encounter within a women's sex shop was tackled by Malina and Schmidt (1997) by using a form of participant observation. The researchers worked as a sex toy sales person, as well as encounters and discussions with customers and semi-structured interviews with the shop owner.

The study of internet behaviour has lead to the development of 'Virtual Ethnography' (Hine, 2000) which uses a combination of observation of behaviour on-line through web-sites, participation in on-line discussions and games, use of email as an interactive channel with informants, informant diaries and face-to-face interviews (Chen, Davies \& Elliott, 2002). 
Advertising and 'brand ecology' has been studied in a variety of ways. Based on Moore's (1993) call for 'audience ethnography,' O'Donohoe (1994) used a combination of small group discussions and personal interviews to explore the uses and gratifications of advertisements in relation to young people. Ritson and Elliott (1999) used a more traditional ethnographic approach of extended fieldwork with 1618 year olds by one researcher volunteering to teach a nationally required media studies class lasting 6 weeks in return for fieldwork access to each school. Typically the media class being taught occupied one hour per day and the researcher spent the rest of the school day immersed in a variety of scholastic contexts. In total almost six months were spent collecting data at the six different school sites. With only a few exceptions the field researcher spent five days a week, six hours a day in each setting. Within this extended period of close contact, many observations were possible of naturally-occurring interactions about advertisements which the researcher was able to video-tape or record in field notes.

\section{Data Recording Methods}

\section{Field Notes}

In the ethnographic tradition an important role is given to the researcher's field notes, these are written records of social activity written up as soon as possible after the event. A list of what should be recorded ideally in order to fully contextualise the action is given by Spradley (1980, p.78): 
Space: the physical place or places

Actor: the people involved

Activity: a set of related acts people do

Object: the physical things that are present

Act: single actions that people do

Event: a set of related activities that people carry out

Time: the sequencing that takes place over time

Goal: the things people are trying to accomplish

Feeling: the emotions felt and expressed

These field notes are a valuable part of the data as they can also record changes in what the researcher sees as significant as their interpretations develop. Linked to field notes are the researcher's personal diary which can be a useful record of the cognitive and emotional experience of the fieldwork.

\section{Photographic and Video-taped Information}

Visual data can be extremely useful in developing interpretations of behaviour including: the temporal flow of events, culturally significant moments, human-object interactions (Arnould and Wallendorf, 1994). They can be used to stimulate discussion with informants, for example Brown et al., 1994) asked their teenage informants to bring with them to interview drawings and photos of their bedrooms as a route into talking about the symbolic meaning of possessions and media artefacts. 


\section{Case Examples of Methods in Use}

\section{The Connected Household Study}

In the spring quarter of 2001, 10 blue-chip companies from sectors ranging from utilities and telecoms to brewing and pay TV partnered in a groundbreaking study into the (e)merging realities of consumption in the Connected Household. The Study used ethnographic research techniques and discourse analysis as the methodology from which to understand how everyday life in the home is being transformed by (and is transforming) technology and media consumption. Different participating companied had very distinct rationales for their involvement. For some a deep understanding of media consumption in a fragmented media space would feed directly into media planning, advertising and media buying strategies. For others, the research would hope to open up product development, channel strategy and innovation opportunities. The research was conducted by a strategy, innovation and insight consultancy in London, the Happy Dog Group, with input from the Centre for Consumer Research at Exeter University. As with the Mobile Consumer Study below, the overall methodology was designed to create for the commercial partners a platform real strategic advantage in their marketplaces (whether through marketing, channel, distribution or brand strategy), rather than a very interesting research process and set of learnings. Ultimately the only value of such a collaborative (in technique and transaction) initiative is how useful it is in opening up insights that are managerially actionable. 
Eleven families were studied, across the UK, and across class and age boundaries, with ethnographers observing and participating in the families everyday activities in and around the home for between 4 and 6 days. During this time video and audio recordings were made of impromptu and timetabled interviews with one or more family member. The transcripts of these interviews were sent to Exeter for discourse analysis whilst the 4 ethnographers brought their field books, videos and thoughts to various multi-disciplinary sessions where the primary insights were discussed, debated and agreed. The final report was presented to the partners during a one day interactive seminar in London.

The 'informant' families were not selected for their technological prowess or latency, rather for their typicality as consumers of wide varieties of technology and media goods, platforms and services. Due to the ethnographic approach the insights generated were myriadic, penetrating and broad, and no case study could cover them all nor the impact they had, and continue to have, on the corporate, brand or product strategy of the partners. However we will focus on a key finding whose importance in strategic decision-making has been clear.

One core theme centred around the role of rooms in the (re)creation of the necessarily distinct cultural meanings within the lived / living habitat, and the critical role of technology and/or media in the symbolic construction of the space. For example, the living room acts as the stage where 'home-ness' and its associated behaviours (most importantly family leisure) can be generated and be performed. The space is on display to all guests and often exists as the mythical (and rarely practised) 
locus for the family to be a family. As such the technology within it must contribute to this role, on both symbolic and functional levels. The TV rules this space, with the product model being the mostly up-to date (even if not most watched) version in the house and its clear role being to suggest, to both members and outsiders, family consumption together of the eminently shareable content on TV. On the contrary, the PC, was not once found within this space, although it had occasionally started out its life in the in this locale before being relegated to the kid's or spare rooms. Analysis suggests that the reasons for this are manifold; its perceived lack of aesthetic appeal (including the "ungainly" wires and peripherals) clashes with the projected image of good 'taste'; the associations from its birthplace in the workplace juxtaposes with the consensual role of the living room being the 'play' arena; and the 'consumption modes' of this platform do not fit, and in many cases jar, with the consumption modes and symbolic roles emerging in the living room. In other words the consumption of the PC / www is increasingly solitary, unshared and un-relaxing, very much a goaloriented activity - browsing is not as yet, the leisure experience window shopping can be. Clear implications emerge. For a technology product / media platform (the two are increasingly considered as distinct 'categories' in error) to be appropriated into today and tomorrow's living space it must be designed to fit within it in terms of its aesthetics and appearance; its symbolic associations with leisure and 'play'; and its ability to be consumed as a shared medium of family 'togetherness'. The chic new video games consoles are (both aesthetically and symbolically resonant), internet on the $\mathrm{TV}$, in its current manifestation is not, and will remain this way unless the content is 'repurposed' from its www origins, becomes eminently shareable and somehow leisurely, and the box that delivers is small, simple and stylish. 


\section{The Mobile Consumer Study}

The Moby Study, like the Connected Household Study, was a collaborative study of consumption but on this occasion designed to enable companies to gain an understanding of the consumption of brands, products, services and advertising 'on the move' - i.e in the gaps between the home and the office / place of 'work'. The Study was carried out in collaboration with 6 organisations (from confectionery to mobile telephony and motoring services corporates) and used a full range of ethnographic methodologies. Again, due to the vast scope of the insight generated we have had to limit this account to an overview of one area of the study - in fact its core focus - the functional, emotional and symbolic meaning of 'mobility' to the 16-35 year old consumer.

A key emerging theme was around the actual meaning and concept of mobility. The Study revealed that the behaviours and practises around mobility create a major problematic for mobility being perceived as simply physically being 'on the move', 'between two places' or 'in transit'. In fact we discovered that consumers understand themselves to be as much 'mobile' in the home or in the office as they are whilst moving, and mobility might better be understood in contemporary culture as being 'distant from a landline / wired connection'. In fact, it appears that due to the pervasiveness of mobile telephony mobility is actually expanding, with more and more purchase and consumption decisions (as well as social and personal decisions) being made when mobile. One can even go as far as to state that mobility to the mobile phone 
owning consumer can include the act of being symbolically mobile between two social roles or rituals, opportunities that the mobile phone opens up. In other words, the consumer today can fulfil and act out a number of previously mutually exclusive social roles (father, boss, son, employee, lover) in the same moment due to the mobile phone's ability to allow one to 'talk' (play and perform) these roles in a very short space of time, whereas previously being tied down to a fixed line prohibits the use of, say, the open plan office to make personal calls.

It is was a clear insight from this ethnography of consumer mobility that mobility can be more usefully (as opposed to correctly) analysed as a set of 'modes of consumption' that are defined by goals, time-scales, locations and activities in context. i.e. the same consumer, in the same place, at the same time, on two different days, can be in two very different 'consumption modes' and respond very differently to the same marketing activity, advertising, product or service offering. However, conventional targeting models based on need-states and occasionality, or even location and lifestyle, neglect these complex, mode-based differences that occur within the same consumer. We believe that by understanding these (and other) consumption modes strategists can better target consumers with new and existing products and brands, delivering offerings that fit with existing cultural and individual frameworks of consumption.

With the younger consumers mobility becomes the freedom for them to do what they want to do outside of the home (the antidote to parental exclamations of "not under my roof!"). Therefore for them mobility allows the opportunity to negotiate their identities through the services and products made available to them on the move. Witness the penetration of such products and services - CD Walkmans, mobile phones, Gameboys - 
and even coffee shops and petrol forecourts where they can hang out until a text message arrives containing the details of where they should move on to next. Furthermore they seem to create patterns of mobility that are purposefully chaotic and changeable, with many purchase decisions being postponed until the last minute and made on the move. This 'Playful Generation' is expert at developing strategies for 'making the most' of mobile time and they appear to break routine for the sake of creating more 'extraordinary moments', delay purchase decisions as long as possible and revel in the thrill of impulsive \& spontaneous purchases. Hence these younger consumers also spontaneously respect sophisticated retail experiences, enriched by multi-media environments and refreshed through constant evolution and innovation, creating dynamic, changing and unpredictable environments.

As consumers become older, mobility seems to be increasingly routinised (often for the sake of safety and security of dependants including pets and employees, not just children). Out of the ordinary mobility is pre-planned as much as possible and, consequently, is more of a special occasion. Journeys and routine mobility are made as predictable as possible. It is key to realise that these consumers do not want to become young again and structure their life accordingly to resist this.

\section{Learning From Doing Ethnography in a Commercial Context}

Although ethnography is increasingly being used in professional strategic planning and consumer insight development it has a number of methodological and theoretical 
challenges to be overcome when being used for commercial objectives, some of which we shall briefly cover below.

A primary challenge for the use of ethnography in planning is the fostering of a clear understanding by the project team, most specifically for the commissioning 'client', about the true value, appropriate usage and limitations of ethnography. Whilst ethnography can deliver on the time/budget/insight needs of a corporation it tends to a) be more expensive that other forms of research due to its immersive nature b) be likely to open up as many questions as it answers and c) not be able to give conclusive results. In other words the insights can be more 'ambiguous', and the insight generation process more 'interpretive' than many organisations are used to. Furthermore, the use of ethnography alone to fulfil on a corporation's research needs is not recommended, nor is the strict adherence to the academic 'rules' of ethnography.

From a supplier's perspective it is vital to ensure that the client (and their internal clients) are clear about the objectives and goals of the project (whilst balancing focus with openness to discover that which we don't know we don't know), and it is extremely useful to involve clients in ongoing in analysis and interpretation to ensure delivery of actionable strategic insight. Unlike the academic world the use of ethnography must be conspicuously valuable (rather than interesting), and the likelihood of this can be increased if strategy planners are involved with field ethnographers in the development of reports, documents and recommendations - we suggest this use of 'on-culture' (ethnographer) and 'off-culture' (strategist) analysis is vital for credibility, rigour and the generation of value. 
As with all planning and research methodologies, it is crucial for those involved to have a clear understanding of the objectives that the research can usefully deliver on, the appropriateness (or not) of using ethnography, the reality of the ambiguity and interpretive tropes (both as a science and over the time of the project) within the approach, and the need to have certain hygiene factors - more than one researcher, triangulation of data from multiple sources, repeat observations and visits with informants and using trained ethnographers not market researchers - whilst acknowledging that year long academic style immersions, full of ivory towered conventions and discipline politics, are simply not tenable in the 'justified' world of commercial business. Above all, ethnographers and strategic planners using ethnography must take responsibility for educating and informing their clients of the trials, tribulations, joys and uniqueness of this most exciting but difficult of research disciplines. 


\section{References}

Adler, P. A. and Adler P. (1994), “Observational Techniques,” in Denzin, N. and Lincoln, Y. (Eds) Handbook of Qualitative Research, London: Sage.

Agar, M. (1996). The Professional Stranger. London: Academic Press.

Alsop, R. (1986), "People-watchers seek clues to consumers' true behavior" Wall Street Journal, Sep. 4, p.29.

Alvesson, M. and Skoldberg, K. (2000), Reflexive Methodology. London: Sage

Arnould, E. and Wallendorf, M. (1994). "Market-Oriented Ethnography: Interpretation Building and Marketing Strategy Formulation." Journal of Marketing Research, XXXl (November)): 484-504.

Brown, J., Dykers, C., Steele, J., and White, A. (1994), "Teenage Room Culture: Where Media and Identities Intersect," Communication Research, vol. 21, 6, 813-827.

Chen, L., Davies, A. and Elliott, R. (2002), "Gender and Identity Play on the Net Raising Men for Fun?" Asia Pacific Advances in Consumer Research, Vol. 5

Downes, D. and Rock, P. (1982). Understanding Deviance. Oxford: Clarendon Press.

Clarke, I., Kell, I., Schmidt, R. and Vignall, C. (1998), "Thinking the Thoughts They Do: Symbolism and Meaning in the Consumer Experience of the 'British Pub'." Qualitative Market Research: An International Journal, Vol. 1 3, 132144 
Fielding, N. (1993). "Ethnography" in Researching Social Life. N. Gilbert (ed). London: Sage.

Geertz, C. (1973). The Interpretation of Cultures. London: Fontana Press.

Gold, R. (1958), "Roles in Sociological Field Observation," Social Forces, 36, 217 223.

Hammersly, M. and Atkinson, P. (1983), Ethnography: Principles and Practice. London: Routledge.

Hine, C. (2000), Virtual Ethnography. London: Sage.

Hochschild, A. (1979). "Emotion Work, Feeling Rules, and Social Structure." American Journal of Sociology 85 (3)): 551-575.

Lever, J. (1981), "Multiple Methods of Data Collection: A Note on Divergence." Urban Life, 10 (2), 199-213.

Lui, W. and Elliott, R. (2002), “Shopper's Paradise - Hong Kong: Poststructuralism and Acculturation.” Asia Pacific Advances in Consumer Research, Vol.5

Malina, D. and Schmidt, R. (1997), "It's Business Doing Pleasure with You: Sh! A Women's Sex Shop Case." Marketing Intelligence and Planning, 15/7, 352360.

Malinowski, B. (1922). Argonauts of the Western Pacific. London: Routledge and Kegan Paul.

O'Donohoe, S. (1994), "Advertising Uses and Gratifications" European Journal of Marketing, Vol. 28, 8/9, 52-75. 
Percy, L., Rossiter, J. and Elliott, R. (2001). Strategic Advertising Management. Oxford: Oxford University Press.

Ritson, M. and Elliott, R. (1999), “The Social Uses of Advertising: An Ethnographic Study of Adolescent Advertising Audiences" Journal of Consumer Research, Vol. 26, 3, 260-277.

Rust, L. (1993), "Observations: Parents and Children Shopping Together" Journal of Advertising Research, July/August, 65-70.

Spradley, J. (1980), Participant Observation. New York: Holt, Rinehart \& Winston

Stocking, G. (1983). Observers Observed. Madison: University of Wisconsin Press.

Van Maanen, J. (1988). Tales of the Field. Chicago: The University of Chicago Press.

Wattanasuwan, K. and Elliott, R. (1999), "The Buddhist Self and Symbolic

Consumption: The Consumption Experience of Teenage Dhammakaya

Buddhists in Thailand." Advances in Consumer Research, Vol. 26. 150-155

Wattansuwan, K. and Elliott, R. (1997), “'I Am What I Consume:’ From Advertising Literacy to Symbolic Consumption." Proceedings of the European Marketing Academy Conference, Warwick. p.2141-2148 